
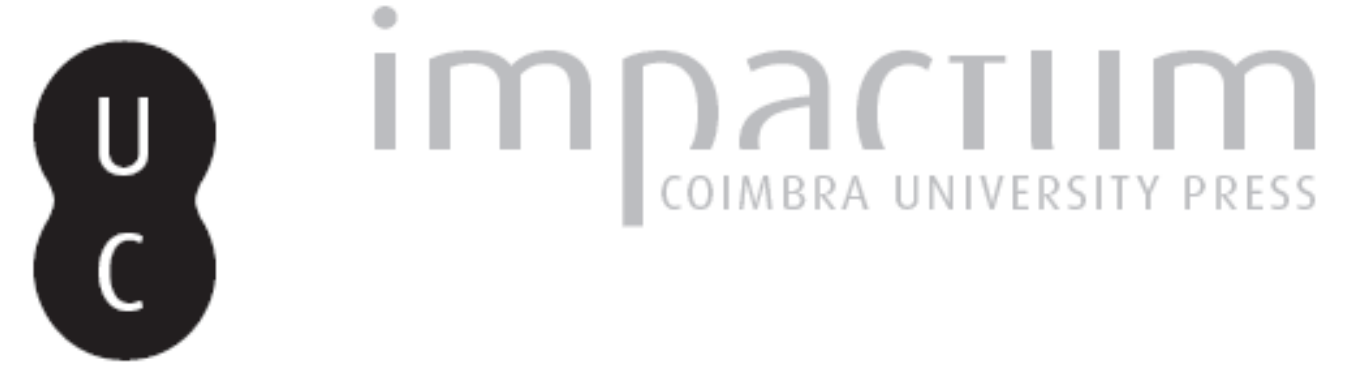

\title{
Marcas da terra sigillata em Alcácer do Sal
}

Autor(es): $\quad$ Faria, João G. Lázaro; Ferreira, Marisol A.; Diogo, A. M. Dias

Publicado por: Imprensa da Universidade de Coimbra

URL persistente:

URl:http://hdl.handle.net/10316.2/45597

DOI:

DOI:https://dx.doi.org/10.14195/1647-8657_26_3

Accessed : $\quad$ 26-Apr-2023 04:01:19

A navegação consulta e descarregamento dos títulos inseridos nas Bibliotecas Digitais UC Digitalis, UC Pombalina e UC Impactum, pressupõem a aceitação plena e sem reservas dos Termos e Condições de Uso destas Bibliotecas Digitais, disponíveis em https://digitalis.uc.pt/pt-pt/termos.

Conforme exposto nos referidos Termos e Condições de Uso, o descarregamento de títulos de acesso restrito requer uma licença válida de autorização devendo o utilizador aceder ao(s) documento(s) a partir de um endereço de IP da instituição detentora da supramencionada licença.

Ao utilizador é apenas permitido o descarregamento para uso pessoal, pelo que o emprego do(s) título(s) descarregado(s) para outro fim, designadamente comercial, carece de autorização do respetivo autor ou editor da obra.

Na medida em que todas as obras da UC Digitalis se encontram protegidas pelo Código do Direito de Autor e Direitos Conexos e demais legislação aplicável, toda a cópia, parcial ou total, deste documento, nos casos em que é legalmente admitida, deverá conter ou fazer-se acompanhar por este aviso.

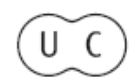


FACULDADE DE LETRAS

INSTITUTO DE ARQUEOLOGIA

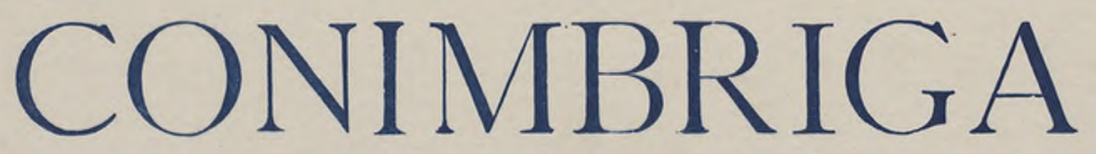

VOLUME XXVI

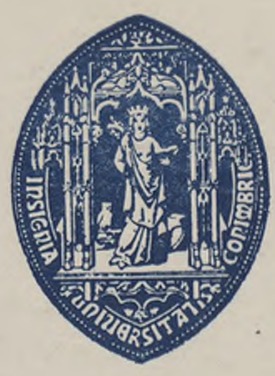

UNIVERSIDADE DE COIMBRA

1987 
Jỗo G. LÁzARO FARIA

Director do Museu de Alcácer do Sal

MARISOL A. FERREIRA

Lie. em História/Arqueologia, pela Faculdade de Letras de Coimbra

A. M. Días Diogo

Assistente da Universidade Nova de Lisboa

MARCAS DA TERRA SIGILLATA DE ALCÁCER DO SAL

Conimbriga, XXVI (1987), p. 61-76

Resumo: Os autores publicam trinta e nove marcas de sigillata inéditas, provenientes de Alcácer do Sal, que confirmam a excepcionalidade da sua importação em relação ao normal para o território português.

SUMmARY: The AA. publish thirty-nine more sigillata stamps from Alcácer do Sal. The exceptionality of the imports is confirmed. 
(Página deixada propositadamente em branco) 


\section{MARCAS DE TERRA SIGILLATA DE ALCÁCER DO SAL}

O presente estudo integra-se no conjunto de trabalhos que temos vindo a realizar sobre o material inédito das colecções do Museu Municipal de Alcácer do Sal. São estudadas 39 novas marcas provenientes de vários locais da povoação $(*)$ e revistas duas anteriormente publicadas $\left({ }^{2}\right)$.

O número de marcas conhecidas de Alcácer fica, assim, elevado para 97, uma amostragem muito significativa, que confirma a excepcionalidade das importações de sigillata em relação ao normal para o território português e as conclusões tiradas em trabalhos anteriores $\left({ }^{3}\right)$.

Presentemente, Alcácer tem $69 \%$ de marcas itálicas (67), 18,5\% de marcas sudgálicas (18) e 12,3\% de marcas hispânicas (12). Embora também aqui contabilizada como sudgálica, a marca de M. VALERIVS deverá ser itálica $\left.{ }^{4}\right)$. $\mathrm{O}$ ponto mais alto das importações atinge-se na última década do séc. I a. C., com 17,9\% das marcas itálicas claramente dessa época, $16,4 \%$ datáveis de 10 a. C. a 10/15 d. G. e $28,4 \%$ genericamente atribuídas à época

(0 Entre os quais se encontra o depósito de água do Castelo. Estas marcas deveriam ter sido publicadas por F. DiAs, no seu estudo sobre as marcas de sigillata de Alcácer. Infelizmente, era política do então responsável pelo Museu manter material fora do alcance dos investigadores.

I (2) HERMEROS, n. ${ }^{\circ} 22$ do Quadro Geral, que A. Alarcão atribuiu a HERMIAS + EROS, 1971, 16, e L. VRRANVS, n. ${ }^{\circ} 62$ do Quadro Geral, que a mesma investigadora atribuiu, interrogando-a, a MVRRANVS, 1971, 33.

(3) Veja-se D. Diogo, 1980, b, c, 1982, 1984.

$\left.{ }^{4}\right)$ Publicada por F. DiAs, 1978, 6, que segue a atribuição de OXÉ-COMFORT 2223, 15. A marca tem, no entanto, uma epigrafia itálica e C. BÉmont, 1975, p. 151, considera-a itálica. 
de Augusto. Dos finais de Augusto-Tibério, apenas são 30\% das marcas. De notar ainda a existência de quatro marcas radiais e três tardo-itálicas, demonstrando estas últimas uma persistência de circuitos comerciais que, no que respeita a marcas, apenas ainda se encontra atestado para Alcácer.

A proveniência do material itálico é variada, com uma natural predominância de Arezzo (74,2\%); Roma e Itália Central contam com 13,6\%, Puzzoles com $7,6 \%$ e apenas duas e uma marcas são atribuíveis, respectivamente, a Pisa e Luna.

As marcas sudgálicas surgem-nos como um conjunto de origem homogénea, sobretudo graças à sua menor importância relativa. Esta cerâmica deverá ser, na totalidade, proveniente de La Graufesenque, e atinge o seu apogeu de importação com Cláudio-Nero, após o que deixa de ser significativa.

Quanto à sigillata hispânica, as doze marcas aparecem-nos repartidas por apenas oito oleiros; também toda ela deverá ser proveniente de apenas um centro produtor, Tricio, e datada sobretudo da 2. ${ }^{\text {a }}$ metade do séc. I. 


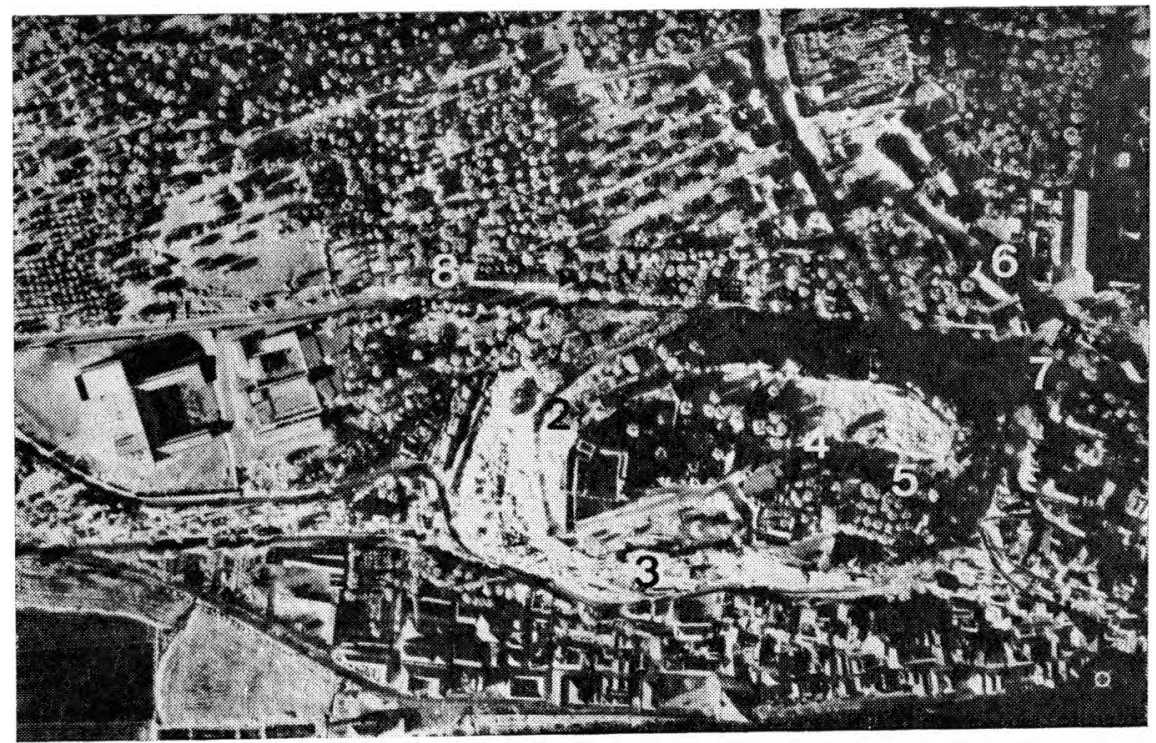

Foto I. - Localização dos achados das marcas 


\section{CATÁLOGO}

1. SEX.ANNI em cartela rectangular alta, de ângulos arredondados, com moldura de ramagens, deficientemente impressa na parte superior (7X17 mm).

Fragmento de fundo de prato, espessura 4,5 mm. Duas ranhuras circulares no fundo interno, de 21 e $23 \mathrm{~mm}$. de diâmetro.

«Verniz» alaranjado, fino e brilhante, superfície exterior com muitas ranhuras circulares. Pasta rosa-clara, muito fina.

Proveniente de São Francisco (6). $\quad$ N. ${ }^{\circ}$ de inv. do Museu 2605.

Trata-se de uma marca de SEXTVS ANN1VS AFER, de Arezzo, que possivelmente trabalhou entre os anos 10 a.C. e 10. Em Portugal apenas era conhecido por outra marca, também de Alcácer.

2. CN.ATE em cartela rectangular alta, ou elíptica, deficientemente impressa nos lados (alt. $6 \mathrm{~mm}$ ).

Fragmento de fundo de taça, espessura 4,5 mm. Ranhura circular de $23 \mathrm{~mm}$. de diâmetro no fundo interno.

«Verniz» laranja-avermelhado, fino, homogéneo e baço, fundo externo parcialmente não envernizado. Pasta beige-rosada, com muito pequenas partículas de calcite e pequenas fendas.

Proveniente do Castelo, lado poente (2). N. ${ }^{\circ}$ de inv. do Museu: 1878.

Cn. ATEIVS, de Arezzo, produziu entre 15/10 a.C. e 20 é o oleiro itálico mais bem representado em território português.

3. ATEI em planta pedis à direita, letras de muito pequeno relevo (4,5X12 mm).

Fragmento de fundo e pé de pequena taça. Pé triangular, de $38 \mathrm{~mm}$. de diâmetro.

«Verniz» alaranjado, fino e homogéneo. Pasta ocre, muito fina e dura. Proveniente do Castelo, lado poente (2). N. ${ }^{\circ}$ de inv. do Museu: 1876. Marca de Cn. ATEIVS.

4. [...]EVHO[...], marca partida à direita e em cima.

Fragmento de fundo de taça, espessura $6 \mathrm{~mm}$. Ranhura circular de $21 \mathrm{~mm}$. de diâmetro no fundo interno.

«Verniz» laranja-escuro, fino, de brilho acetinado, com muitas ranhuras circulares na superfície externa. Pasta rosada, fina, com pequenas fendas.

Proveniente do Castelo, depósito (4). N. ${ }^{\circ}$ de inv. do Museu: 4418. Marca de EVHODVS, de Cn. ATEIVS, a difusão dos seus produtos parece ter-se iniciado nos começos da nossa era. Já conhecido em Conimbriga, Represas e, talvez, Tróia. O estado de conservação desta marca não permite saber se era bilínea, completa com o nome de patronus. 


\begin{tabular}{|c|c|c|c|c|c|c|c|}
\hline $\begin{array}{c}\text { N.o } \\
\text { Ordem }\end{array}$ & Oleiro & Marca & Forma & Oficina & Cronologia & Loc. & Bibliografia \\
\hline 1 & SEXTVS ANNIVS AFER & {$[\mathbb{E}] \mathrm{SEX} /[\mathbb{E}] \overline{\mathrm{AN}} \mathrm{NI}$} & G. 23 & Arezzo & 10 a. C. -10 d. C. & 1 & A. Alarcĩo, 1971, 2 \\
\hline 2 & SEXTVS ANNIS AFER & SEX. ANNI & Prato & $"$ & " " " & 1 & N. ${ }^{\circ} 1$ \\
\hline 3 & CN. ATEIVS & GN $\cdot \overline{\mathrm{ATE}}$ & Taça & $"$ & 15/10 a. C. -20 d. C. & 1 & N.o 2 \\
\hline 4 & CN. ATEIVS & ATEI (p.p.) & Taça & $"$ & " " & 1 & N. ${ }^{\circ} 3$ \\
\hline 5 & EVHODVS & {$[\cdots]$ EVHO $[\cdots]$} & Taça & $"$ & 1. a década da nossa era & 4 & $\mathrm{~N} .{ }^{0} 4$ \\
\hline 6 & AVILLIVS & AVI $\cdots \cdots$ & - & $"$ & Augusto-Tibério & 1 & A. Alarcão, 1971 \\
\hline 7 & $\mathrm{P} \cdot \mathrm{G} \cdot \mathrm{N}$ & $P \cdot C \cdot N$ & Prato & Roma? & Último quarto do séc. I a. C. & 2 & N.o 5 \\
\hline 8 & P. CORNILIVS & {$[\cdots]$ P.CORNE } & Prato & Arezzo & Finais Augusto-Tibério & 8 & N.० 6 \\
\hline 9 & EPIGONVS P.CORNELI & $\mathrm{EPIGO} /[\mathrm{P} \cdot \mathrm{C}] \mathrm{OR}$ & Prato & $"$ & Augusto & 4 & F. DiAs, 1978, 2 \\
\hline 10 & EPIGONVS P.CORNELI & EPIGO/P·COR & Prato & 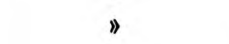 & " & 2 & N.o 7 \\
\hline 11 & MEMOR P. CORNELI & $\mathrm{P} \cdot \mathrm{CO} \overline{\mathrm{RNE}} /[\mathbb{N}] \overline{\mathrm{MEN}}$ & - & $"$ & Finais Augusto-Tibério & 1 & A. Alargão, 1971, 32 \\
\hline 12 & PRIMVS P. CORNELI & PRIMVS/P.CORNEL (externa) & Drag. V & " & " " " & 1 & A. Alarcão, 1971, 41 \\
\hline 13 & A.CORONCANIVS & A/CORON/CAN & G. 27 & Puzzoles & Anterior à nossa era & 2 & D. Diogo, 1982, n. 1 \\
\hline 14 & CRESTVS & $\mathrm{CRE}[\mathrm{STI}]$ & Prato & Arezzo? & Finais Augusto-Tibério & 1 & N.0 8 \\
\hline 15 & C.CRISPINIVS & CRIS/PINI & Prato & Arezzo & 10 a. C. -10 d. C. & 2 & D. Diogo, $1984 \mathrm{c}, 4$ \\
\hline 16 & $\mathrm{C} \cdot \mathrm{CR}$ ISPINIVS & 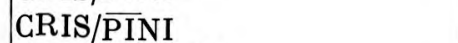 & Taça & $"$ & $" \quad "$ & 2 & N.o 9 \\
\hline 17 & CRISPINI IVGVNDVS & CRISPIN/IVC & Taça & " & $" \quad "$ & 2 & D. Diogo, 1982, n. 1 \\
\hline 18 & C.CVRTIVS RVFVS & [C·]CVRTI & - & Itália Central? & Augusto & 1 & A. Alaraz̃a $0,1971,44$ \\
\hline 19 & FAVSTVS & FAVS/TVS & - & $"$ & " & & A. Alarã̃o, 1971, 19 \\
\hline 20 & L.GELLIVS & L.GELI & Prato & Arezzo & Augusto-Tibério & 4 & F. DIAS, 1978,3 \\
\hline 21 & HERACLIO & HII/ACLI[O] & G. $27 ?$ & Roma & $\begin{array}{l}\text { Augusto } \\
\text { Austo }\end{array}$ & 2 & D. Diogo, 1982, 1 \\
\hline 22 & HERMEROS & ERM/EROS & G. 13 ou 18 & Roma? & " & 1 & A. Alarcĩo, 1971, 16 \\
\hline 23 & P.HERTORIVS & PHERT & - & Arezzo & Último quarto séc. I a. C. & 2 & N.o 10 \\
\hline 24 & MAHES & MAHEI & Taça & Roma? & Augusto & 2 & N.o 11 \\
\hline 25 & $\mathrm{C} \cdot \mathrm{ME} \cdot \mathrm{VIBIVS}$ & $\mathrm{C} \cdot \mathrm{ME} / \mathrm{VIBIV}$ & Taça & Itália Central & Finais de Augusto-Tibério & 8 & D. Diogo, 1980 c, 10 \\
\hline 26 & C.MEMMIVS & MEMM & G. 13 & Arezzo & Augusto-Tibério & 2 & D. Diogo, 1980 c, 9 \\
\hline 27 & C.MEMMIVS & $\overline{\mathrm{ME}} \mathrm{MMI}$ & G. 16 & $"$ & " " " & 2 & N.o 12 \\
\hline 28 & S.MVRRIVS FESTVS & SEX M:F (p.p.) & - & Luna & Cláudio-Vespasiano & 1 & A. Alargão, 1971, 20 \\
\hline 29 & AGATHEMERVS NAEVI & AGA/ $/ \overline{N A} E V I$ & Taça & Puzzoles & Augusto & 4 & F. DiAs, 1978,1 \\
\hline 30 & L·NOSTIVS & $L \cdot$ NOSTI & Taça & Puzzoles? & " & 4 & N.o 13 \\
\hline 31 & C.P.P & C.P.P (p.p.) & - & Pisa? & Cláudio-Vespasiano & 1 & A. Alargão, 1971, 38 \\
\hline 32 & C.P.P & $\mathrm{C} \cdot \mathrm{P} \cdot \mathrm{P}(p \cdot p \cdot)$ & Prato & $"$ & " " " & 2 & N. ${ }^{0} 14$ \\
\hline 33 & M·PERENNIVS & M.P[ERENNI $]$ & - & Arezzo & Augusto-Tibério & 4 & F. DiAs, 1978,4 \\
\hline 34 & SEXTVS PETRONICVS & $\mathrm{S} \cdot \overline{\mathrm{PE}}(r)$ & G. $12 ?$ & $"$ & Anterior à nossa era & 2 & D. Diogo, 1982, n. 1 \\
\hline 35 & L. et C. PETRONIVS CORIA & $\mathrm{L} \cdot \mathrm{C} \cdot \mathrm{PE}[\cdots] / \mathrm{CORI}$ & - & $"$ & Augusto & 2 & D. Diogo, 1980 c, 8 \\
\hline 36 & RASINIVS & RASN & G. 30 & $"$ & 10 a. C. -15 d. C. & 2 & D. Diogo, 1980 c, 11 \\
\hline 37 & RASINIVS & RAS & Prato & $"$ & " " " & 2 & N.o 15 \\
\hline 38 & RASINIVS & RASI $\overline{N I}$ & Prato & $"$ & " & 2 & N.o 16 \\
\hline 39 & CELER RASINI & CELER,RASIN & G. 39c. & " & " & 1 & A. Alarcĩo, 1971 \\
\hline 40 & CELER RASINI & GELER/RASIN & - & $"$ & " & 4 & F. DIAS, 1978,5 \\
\hline 41 & L.SAVFEVS GAVSA & $L / \cdots / \cdots$ & - & $"$ & Augusto-Tibério & 1 & A. Alarcĩo, 1971, 24 \\
\hline 42 & C.SENTIVS & C.SENTI & Prato & $"$ & $" \quad "$ & 2 & D. Diogo, 1980 c, 12 \\
\hline 43 & FELIX SERGI & [FE] LIX/SER[GI] & G. 25 ou 27 & Arezzo? & Augusto & 2 & N.o 17 \\
\hline 44 & SESTIVS? & S.ES ou SES & Taça & ." & $" \quad "$ & 2 & D. Drogo, 1982,3 \\
\hline 45 & HILARIVS A. SESTI DAMAE & HILA $[\cdots] /[\mathrm{A}] \cdot$ SEST & Taça & Arezzo & Fins do séc. I a. C. & 2 & D. DIOGO, 1982, 2 \\
\hline 46 & HILARIVS A. SESTI DAMAE & HILARI/A.SEST $[\cdots](r)$. & G. 17 & " & Augusto & 2 & D. Diogo, $1980 \mathrm{c}, 7$ \\
\hline 47 & ANTEROS STATIVS & ANTERO/STATII & - & Arezzo? & 12/10 a. C.-12/16 d. C. & 2 & D. DIOGo, $1980 \mathrm{c}, 1$ \\
\hline 48 & SVAVIS STATIVS & SVAVI/STATI & - & $"$ & Augusto-Tibério? & 2 & D. Diogo, 1980 c, 15 \\
\hline 49 & L.TETTIVS SAMIA & L.TETI /S $\overline{A M I A}$ & - & Arezzo & 20 a. C. -0 & 1 & A. Alargão, 1971, 47 \\
\hline
\end{tabular}


5. P.C.N. em cartela rectangular alta $(5 \mathrm{X} 13 \mathrm{~mm})$.

Fragmento de fundo de prato, espessura $5 \mathrm{~mm}$. Com duas ranhuras circulares largas, de 9 e $13 \mathrm{~mm}$ de diâmetro no fundo interno. «Verniz» laranja-escuro, fino, de brilho acetinado, superfície externa não invernizada. Pasta rosa-clara, fina.

Proveniente do Castelo, lado poente (2). N. ${ }^{\circ}$ de inv. do Museu: 1861. $\mathrm{P}(\ldots) \mathrm{C}(\ldots) \mathrm{iV}(\ldots)$, O-C 350 , talvez oleiro de Poma, produziu no último quartel do séc. I a.C. Surge-nos agora pela primeira vez em Portugal, já tinha aparecido em Elche, Florença, Roma e Tarragona.

6. P..CORNE com risco horizontal no lado superior, marca rectangular, muito danificada, partida à direita e em baixo.

Fragmento de fundo de prato, espessura $6,5 \mathrm{~mm}$.

«Verniz» alaranjado, manchado, de brilho acetinado, pouco espesso

e degradado. Pasta rosa-alaranjada, fina e pulverulenta.

Proveniente da Azinhaga do Sr. dos Mártires (8). N. ${ }^{\circ}$ de inv. do

Museu: 5295.

P.CORNELIVS, oleiro de Arezzo, datado dos finais de Augusto-Tibério ou Tibério. Largamento difundido em Portugal, já era conhecido em Alcácer através dos seus escravos EPIGONVS, MEMOR e PRIMVS.

7. EPIGO/P.COR bilínea, em carteia troncocònica, bilobada à direita e trilobada à esquerda. Deverá ser uma marca acidental, provocada por deficiência de estampilhagem do nome do escravo $(8 X 14,5 \mathrm{~mm})$. Fundo de prato, espessura $6 \mathrm{~mm}$. Fundo interno decorado com uma banda de guiloché muito fino.

«Verniz» laranja-avermelhado, fino, bem aderente e brilhante. Pasta laranja-rosada, fina e dura.

Proveniente do Castelo, lado poente (2). N. ${ }^{\circ}$ de inv. do Museu: 4841. EPIGONVS, de Arezzo, um dos oleiros mais aniigos de P.CORNELIVS, já era conhecido em Alcácer.

8. $\mathrm{CRE}[\mathrm{STI}]$ em carteia bífida, com moldura linear paralela à cartela, partida à direita (alt. $4 \mathrm{~mm}$ ). Paralelo exacto'em O-C 425, 74, de Vechten.

Fragmento de fundo de prato, espessura $8 \mathrm{~mm}$. Ranhura circular no fundo interior de $24 \mathrm{~mm}$ de diâm.

«Verniz» alaranjado, degradado, de brilho acetinado, superfície exterior com muitos riscos concêntricos. Pasta rosa-clara, fina e dura, com pequeníssimas fendas.

Proveniente da Estrada Nacional 5 (7). N. ${ }^{\circ}$ de inv. do Museu: 4842. CRESTVS, itálico, possivelmente de Arezzo, poderá ser oleiro de 
vários patroni; a sua correda atribuição exigirá um cuidadoso estudo das diferentes marcas. Será datado dos finais de Augusto-Tibério. Com grafia semelhante já apareceu em Conimbriga.

9. CRIS/PINI, bilínea em quadrado quadrilobado.

Fundo e pé de taça (Est. II), forma G.27. Pé triangular, oblíquo, fundo muito côncavo. Ranhura circular no fundo interno de $19 \mathrm{~mm}$ de diâm. Diâmetro do pé $39 \mathrm{~mm}$.

«Verniz» alaranjado, fino, bem aderente, de brilho baço. Pasta ocre-rosada, muito fina.

Proveniente do Castelo, lado poente (2). N. ${ }^{\circ}$ de inv. do Museu : 5296. C.CRISPINIVS, de Arezzo, produziu entre 10 a.C. e 10 . Já estava atestado em Alcácer, só e com o seu oleiro IVCVNDVS.

10. PHERT em cartela rectangular alta, decorada em cima e em baixo com triângulos envolvidos por volutas, partida à direita (alt. $12 \mathrm{~mm}$ ). É possível que não tivesse qualquer outra letra após o $\mathrm{T}$, já que a decoração deverá ser centrada e nota-se o arredondamento do canto inferior direito da carteia.

Fragmento de fundo, espessura $3,5 \mathrm{~mm}$.

«Verniz» laranja-avermelhado, fino e homogéneo, de brilho acetinado. Pasta ocre-acinzentada, muita fina, com pequenas fendas Proveniente do Castelo, lado poente (2). N. ${ }^{\circ}$ de inv. do Museu: 1870. P.HERTORIVS é um dos mais antigos oleiros de Arezzo, datável do último quartel do séc. i a.C. Está largamente atestado na Itália, África do Norte e Espanha, surge agora em Portugal pela primeira vez.

11. MAHEI em cartela rectangular $(4 \times 7,5 \mathrm{~mm})$. Letras de pequeno relevo.

Fragmento de fundo de taça, muito côncava, espessura $4,5 \mathrm{~mm}$. «Verniz» alaranjado, fino e brilhante. Pasta beige-rosada, dura, com pequenas partículas de calcite muito abundantes e alguns pequenos nódulos ocres.

Proveniente do Castelo, lado poente (2). N. ${ }^{\circ}$ de inv. do Museu: 1867. $M A H$ ES é um oleiro de Roma ou da Itália central, da época de Augusto. Tem larga difusão: Itália, França, Alemanha, Suíça, Espanha (Tarragona e Ampúrias), Corinto. Aparece agora pela primeira vez em Portugal.

12. MEMMI em cartela rectangular $(6 \times 12,5 \mathrm{~mm})$.

Fundo de taça (Est. II), forma G.16. Pé fino, triangular. Superfície interna com ranhura circular de $15 \mathrm{~mm}$ de diâm. e um ressalto na junção com a parede. Diâmetro do pé $50 \mathrm{~mm}$. 
«Verniz» alaranjado, fino, homogéneo e brilhante. Pasta ocre-amarelada, muito fina e pulverulenta.

Proveniente do Castelo, lado poente (2). N. ${ }^{\circ}$ de inv. do Museu: 1863. C.MEMMIVS de Arezzo, período Augusto-Tibério. Já estava atestado em Alcácer.

13. L.NOSTI em cartela rectangular de ângulos muito arredondados, partida à esquerda (alt. $5 \mathrm{~mm}$ ). Paralelo exacto em O-C 1142, aFragmento de fundo de taça, espessura $4 \mathrm{~mm}$.

«Verniz» laranja-avermelhado, fino e homogéneo, de brilho acetinado, superfície externa com muitas ranhuras em espiral. Pasta beige-amarelada, com abundantes pequenas partículas de calcite. Proveniente do Castelo, depósito (4). N. ${ }^{\circ}$ de inv. do Museu: 3493. $L$.NOSTI VS é um oleiro itálico pouco conhecido e de difusão muito reduzida; apareceu em Puzzoles, onde talvez ficasse o seu centro de produção.

14. C.P.P. retrógrada, em planta pedis à esquerda, partida à direita (5X23 mm).

Fragmento de fundo de prato muito espesso, esp. $11 \mathrm{~mm}$.

«Verniz» laranja-avermelhado, pouco aderente, pouco cuidado e de brilho baço, superfície externa não envernizada. Pasta rosa-clara, fina e dura, com muitas fendas.

Proveniente do Castelo, lado poente (2). N. ${ }^{\circ}$ de inv. do Museu: 5248. $C(\ldots) \mathrm{P}(\ldots) \mathrm{P}(\ldots)$ é um oleiro talvez de Pisa, do período Cláudio-Vespasiano. Já tinha aparecido em Alcácer.

15. RAS em cartela rectangular, partida no canto superior direito (5X9 mm).

Fragmento de fundo de prato. Superfície interna com ranhura de 45 mm de diâm.

«Verniz» laranja-acastanhado, manchado, fino, de brilho acetinado, com muitas ranhuras circulares no fundo externo. Pasta beige-amarelada, muito fina.

Proveniente do Castelo, lado poente (2). N. ${ }^{\circ}$ de inv. do Museu: 1864. RASINIVS de Arezzo, deve ter começado a produzir por volta de 10 a.C. e terminado por volta de 20. Já tinha surgido em Alcácer.

16. RASINI em cartela rectangular alta, com moldura em espinha (7X14 mm).

Fragmento de fundo de prato, espessura $5 \mathrm{~mm}$.

«Verniz» laranja-acastanhado, fino, de brilho acetinado; fundo externo não invernizado. Pasta beige-rosada, muito, fina.

Proveniente do Castelo, lado poente (2). N. ${ }^{\circ}$ de inv. do Museu: 1860.

Marca de RASINIVS.

Conimbriga, 26 (1987), 61-76 
17. [FE]LIX / SER[GI] bilinea, em cartela circular, parcialmente mal impressa e partida na parte inferior direita (diâm. $11 \mathrm{~mm}$ ). O-C 1750, com paralelo exacto.

Fundo de taça (Est. II), forma G.25 ou 27. Pé triangular, superfície interna com ranhura de $14 \mathrm{~mm}$ de diâm. Diâmetro do pé $38 \mathrm{~mm}$. «Verniz» alaranjado, fino, de brilho baço. Pasta ocre-rosada, com muitas pequenas partículas de calcite.

Proveniente do Castelo, lado poente (2). N. ${ }^{\circ}$ de inv. do Museu: 1869. FELIX, oleiro de SERGI VS, possivelmente de Arezzo e da época de Augusto. As marcas conhecidas mostram uma dispersão na Itália e em Espanha (Ampúrias e Tarragona).

18. SARIVA / L.TETTI bilínea em cartela rectangular $(6 \mathrm{X} 11 \mathrm{~mm})$. Ùltimo A em nexo com o $\mathrm{V}$ e de muito pequeno relevo.

Fundo de taça (Est. II), forma G.25 ou 27. Pé triangular, superfície interna com duas ranhuras concêntricas, de 28 e $30 \mathrm{~mm}$ de diâm. Diâmetro do pé $44 \mathrm{~mm}$.

«Verniz» alaranjado, fino, de brilho acetinado. Pasta ocre, dura, muito fina.

Proveniente do Castelo, lado poente (2). N. ${ }^{\circ}$ de inv. do Museu: 1880. SARIVA, oleiro de L.TETTIVS SAMIA, de Arezzo, datado dos últimos 20 anos do séc. i a.C. Representado na Espanha, França Itália e Grécia, é a primeira vez que aparece em território português. L. TETTIVS SAMIA já se encontrava bem atestado em Alcácer.

19. S.TI/TIVS, marca radial, bilínea, em cartela rectangular $(5,5 \times 5$ $\mathrm{mm})$. Letras formadas por pontos, $\mathrm{V}$ fechado por deficiente estampilhagem, dando a impressão de ser um $O$.

Fundo de pequeno prato (Est. II). Pé em cabeça de martelo, superfície interna decorada com uma banda de guiloché. Diâmetro do pé $72 \mathrm{~mm}$.

«Verniz» laranja-avermelhado, fino, de brilho acetinado. Pasta ocre-rosada, fina e branda.

Proveniente do Castelo, lado poente [2). N. ${ }^{\circ}$ de inv. do Museu: 1865. S. TITIVS, de Arezzo, datável do último quartel do séc. I a.C. Surge pela $1 .^{a}$ vez em Portugal, está atestado na Itália e em Espanha (Ampúrias).

20. CRV[S]TVR[A] em cartela rectangular, bilínea, separada por um traço, partido à direita (alt. $8 \mathrm{~mm}$ ). Paralelo exacto em O-C 2200, b. Fragmento de fundo de pequena taça, forma G.29. Espessura do fundo $2,5 \mathrm{~mm}$. Ranhura circular interna de $30 \mathrm{~mm}$ de diâmetro. «Verniz» alaranjado, fino e homogéneo, de brilho acetinado. Pasta ocre-rosada, fina, de aspecto micro-granuloso.

Proveniente do Castelo, lado poente (2). N. ${ }^{\circ}$ de inv. do Museu: 1879. 
CHRYSES, oleiro de C. VALERI VS TVRANNIVS, é pouco conhecido; a maioria das suas marcas apareceu em Roma, de onde talvez seja originário. Deverá ser datado da época de Augusto. Marcas semelhantes às de Alcácer apareceram em Roma e Cartago.

21. G.YBE em planta pedis à direita, partida à esquerda (alt. $5 \mathrm{~mm}$ ).

Fragmento de fundo.

«Verniz» laranja-avermelhado, homogéneo, de brilho baço. Pasta rosa-clara, fina e dura.

Proveniente do Castelo, depósito (4) N. ${ }^{\circ}$ de inv. do Museu: 3489. C. VIRIENVS, de Arezzo, período Augusto-Tibério. Em Portugal já tinha sido encontrada em Balsa e nas Represas.

22. VILLI em planta pedis, talvez à direita, partida em ambos os lados (alt. 5,5 mm).

Fragmento de fundo, espessura $5 \mathrm{~mm}$.

«Verniz» vermelho-acastanhado, fino e pouco aderente, de brilho acetinado. Pasta beige-amarelada, muito fina.

Proveniente do Castelo, lado poente (2). N. ${ }^{\circ}$ de inv. do Museu: 1532. SEX. VILLIVS NATALIS, oleiro de Arezzo, dos finais de Augusto-Tibério, já tinha sido encontrado em Alcácer.

23. VILL em planta pedis à direita, partida à direita (alt. $4,5 \mathrm{~mm}$ ), Fragmento de fundo, espessura $6 \mathrm{~mm}$.

«Verniz» alaranjado, de brilho acetinado, pouco aderente e degradado. Pasta rosa-clara, fina e dura, com algumas pequenas fendas. Proveniente do Castelo, açougues (5). N. ${ }^{\circ}$ de inv. do Museu: 1013. Marca de SEX. VILLIVS NATALIS.

24. L. VRBA em cartela rectangular alta, de ângulos arredondados e moldura de pontos $(5 \times 10,5 \mathrm{~mm})$.

Fragmento de fundo, espessura $5 \mathrm{~mm}$.

«Verniz» alaranjado, fino e brilhante, Pasta beige-rosada, fina e dura, com algumas pequenas fendas.

Proveniente do Castelo, lado poente (2). N. ${ }^{\circ}$ de inv. do Museu: 1868. L. VRRANVS, de Puzzoles, da época de Augusto, surge pela 2. ${ }^{\text {a }}$ vez em Alcácer, único local onde, até ao momento, se encontra atestado em Portugal.

25. Marca anepígrafa: sandália voltada à direita $(4,5 \times 15 \mathrm{~mm})$.

Fragmento de fundo de taça, espessura $4 \mathrm{~mm}$.

«Verniz» alaranjado, fino e homogéneo, de brilho acetinado, abundantes pequenas ranhuras em espiral na superfície externa. Pasta ocre-amarelada, compacta, de aspecto micro-granuloso. 
Proveniente do Castelo, depósito (4). N. ${ }^{\circ}$ de inv. do Museu: 3492. Trata-se de uma marca itálica, para a qual não encontrámos paralelo. A sua datação deverá ser finais de Augusto-Tibério.

26. ACYTVS em cartela rectangular de ângulos muito arredondados (3X15,5 mm).

Fragmento de fundo e pé de pequena taça. Pé triangular de larga base de sustentação, ranhura circular no fundo interno de $15 \mathrm{~mm}$. de diâm. Diâmetro do pé $36 \mathrm{~mm}$.

«Verniz» laranja-avermelhado, fino e homogéneo, de brilho baço. Pasta laranja-acastanhada, compacta, fina e dura, com pequenas partículas de calcite.

Proveniente da Azinhaga do Sr. dos Mártires (8). N. ${ }^{\circ}$ de inv. do Museu: 5297.

ACVTVS, tido como um dos oleiros mais antigos de Montans, foi integrado, através de análises de pastas, por C. BÉmont (p. 15), entre os produtores de La Graufesenque, o que convém a Alcácer. É datável de Tibério-Nero. Em Portugal já tinha surgido nas Represas e em Torre de Palma.

27. ALBV[...] em cartela rectangular de ângulos arre ndondadcs, par tida à direita e em baixo.

Fragmento de fundo de taça, espessura $3 \mathrm{~mm}$.

«Verniz» alaranjado, fino e brilhante. Pasta rosa-alaranjada, muito fina.

Proveniente do Castelo, lado poente (2). N. ${ }^{\circ}$ de inv. do Museu : 4882. $A L B V S$ é um oleiro de La Graufesenque, do período Cláudio-Nero. Em Portugal já tinha sido encontrado na Egitânia e nas Represas.

28. F. CAST em cartela rectangular $(3 \times 15 \mathrm{~mm})$.

Fundo e pé de prato (Est. II). Pé triangular, ranhura circular no fundo interno, de $54 \mathrm{~mm}$ de diâm. Diâmetro do pé $74 \mathrm{~mm}$. «Verniz» vermelho-vinoso, homogéneo, de brilho baço. Pasta rosada, dura, com pequenas partículas de calcite.

Proveniência desconhecida (1). N. ${ }^{\circ}$ de inv. do Museu: 643.

CASTVS, de La Graufesenque, do período Cláudio-Vespasiano, tem larga difusão em Portugal: já foi encontrado no Castro de Fiães da Feira, Marim, Monte Molião, Represas, Egitânia e Beja.

29. OFCAS[...] em cartela rectangular de ângulos arredondados, partida à direita (alt. 2,2 mm). O mal impresso.

Fragmento de fundo de taça, espessura $5 \mathrm{~mm}$. Ranhura larga de $13 \mathrm{~mm}$ de diâm. na superfície interna.

«Verniz» laranja-avermelhado, homogéneo e brilhante. Pasta 
amarelada, dura, com partículas de calcite muito abundantes. Proveniente do Castelo, depósito (4). N. ${ }^{\circ}$ de inv. do Museu: 3490. Marca do oleiro CASTVS.

30. DARRAF em carteia rectangular de ângulos muito arredondados (4X17 mm).

Fragmento de fundo de taça, espessura 5,5 mm. Ranhura larga na superfície interna, de $11 \mathrm{~m}$. de diâm.

«Verniz» laranja-avermelhado, brilhante e pouco aderente. Pasta rosa-clara, dura e fina.

Proveniente do Castelo, depósito (4). N. ${ }^{\circ}$ de inv. do Museu: 3494. $D A R R A$ é um oleiro de La Graufesenque, do período Cláudio-Nero. É a primeira vez que é atestado em território português.

31. OF FRONTINI em cartela rectangular de ângulos arredondados, partida à direita (alt. 4,5 mm). $\mathrm{F}$ inicial inscrito no $\mathrm{O}$, I final muito ténue.

Fragmento de fundo e pé de prato (Est. II), forma Dragendorff 15/17. Pé espesso, oblíquo. Fundo côncavo, com uma ranhura circular de $64 \mathrm{~mm}$. de diâm. Diâmetro do pé $87 \mathrm{~mm}$.

«Verniz» laranja-avermelhado, espesso, um pouco estalado, de brilho baço. Pasta rosa-acastanhada, clara, com abundantes partículas de calcite e algumas fendas.

Proveniente do Castelo, depósito (4). N. ${ }^{\circ}$ de inv. do Museu: 3487. FRONTIN VS, oleiro de La Graufesenque, do período Nero-Trajano. Em Portugal já se encontrava atestado em Conimbriga e Portalegre.

32. [...]OFIVÇ $[\ldots]$ em cartela rectangular, partida à direita e à esquerda (alt. 3,5 mm).

Fragmento de fundo de pequena taça, espessura $3 \mathrm{~mm}$.

«Verniz» alaranjado, fino e homogéneo. Pasta laranja-clara, dura, com pequenas partículas de calcite.

Proveniente da Azinhaga do Sr. dos Mártires (8). N. ${ }^{\circ}$ de inv. do Museu: 4883.

IVCVNDVS, de La Graufesenque, período Tibério-Flávios. Já tinha surgido em Alcácer.

33. PAESTOR em cartela rectangular com os ângulos muito arredondados (3X16 mm). P mal impresso, $\mathrm{R}$ de menor relevo do que as outras letras.

Fragmento de fundo de tigela. Marca impressa sobre uma larga ranhura de $13 \mathrm{~mm}$ de diâmetro.

«Verniz» laranja-avermelhado, de brilho baço. Pasta rosa-alaranjada, fina e compacta. 
Proveniente da zona de São Francisco (6). N. ${ }^{\circ}$ de inv. do Museu: 637. PAESTOR é um oleiro pouco conhecido de La Graufesenque, datado de Cláudio. Já foi encontrado na Alemanha e na França, é a primeira vez que aparece em Portugal.

34. OFPVDE em cartela rectangular de ángulos arredondados $(4 \times 18 \mathrm{~mm})$.

Fundo e pé de taça (Est. II), talvez uma forma Dragendorff 27. Pé alto, triangular, com um chanfro sob a carena. Pequeníssima espessura do fundo. Diâmetro do pé $52 \mathrm{~mm}$.

«Verniz» avermelhado, pouco cuidado e brilhante. Pasta rosa-escura, dura, com raras calcites grandes.

Proveniente do Castelo, lado poente (2). N. ${ }^{\circ}$ de inv. do Museu : 1871. PVDENS, de La Graufesenque, datável de Cláudio a c. 75/85. Surge pela 1. ${ }^{a}$ vez em Alcácer, após já estar atestado em Braga.

35. SENICIOF em cartela rectangular de ângulos arredondados, partida à direita em baixo $(3 \times 16,5 \mathrm{~mm})$.

Fragmento de fundo e pé de pequena taça (Est. II), talvez forma Dragendorff 24/25. Pé espesso, triangular. Ranhura circular no fundo interno de $14 \mathrm{~mm}$ de diâm. Diâmetro do pé $41 \mathrm{~mm}$. Tem uma estrela de riscos cruzados, esgrafitada no fundo externo.

«Verniz» laranja-avermelhado, de brilho acetinado, pouco espesso e degradado. Pasta alaranjada, branda, com abundantes calcites. Proveniente da Azinhaga do Sr. dos Mártires (8). N..$^{\circ}$ de inv. do Museu: 5298.

SENICIO, de La Graufesenque, datável de Tibério até c. de 60, aparece agora pela $1 .{ }^{\mathrm{a}} \mathrm{vez}$ em Portugal.

36. Marca aparentemente anepígrafa, formada por círculos unidos, com um ponto central em cada círculo, em cartela rectangular, partida num dos lados (alt. $3 \mathrm{~mm}$ ).

Fragmento de fundo e pé de pequena tigela, possivelmente uma forma Dragendorff 24/25. Pé largo, quase rectangular, pequeno, bifacetado na face externa. Diâmetro do pé $53 \mathrm{~mm}$.

«Verniz» vermelho-alaranjado, homogéneo, de brilho acetinado. Pasta rosada, fina e dura, com algumas partículas de calcite visíveis.

Proveniente do Castelo, lado poente (2). N. ${ }^{\circ}$ de inv. do Museu: 1866. Trata-se de uma marca sudgálica, para a qual não encontrámos paralelo.

37. ATTI.PAf..] em cartela rectangular de ângulos arredondados, partida à direita (alt. $3 \mathrm{~mm}$ ). A sem traço horizontal.

Fragmento de fundo, espessura $4,5 \mathrm{~mm}$. 
«Verniz» laranja-avermelhado, homogéneo e brilhante. Pasta rosa-acastanhada, dura, com abundantes calcites.

Proveniente do Castelo, açougues (5). N. ${ }^{\circ}$ de inv. do Museu: 1014. ATTIVS PATERNVS, oleiro hispânico, de Tricio, datável da $2 .^{\mathrm{a}}$ metade do séc. i, inícios do $n$. Já se encontrava atestado em Alcácer.

38. CANTABRI em cartela rectangular $(4 \times 23 \mathrm{~mm})$. Letras de alto relevo, A sem traço horizontal.

Fragmento de fundo, e pé de taça (Est. II), forma Dragendorf 33. Pé espesso, oblíquo, de larga superfície de sustentação. Superfície interna com uma ranhura circular de $23 \mathrm{~mm}$ de diâm., ressalto interno e chanfro externo na junção da parede com o fundo. Diâmetro do pé: $42 \mathrm{~mm}$. Tem um grafito «MS» gravado no fundo interno.

«Verniz» alaranjado, homogéneo e brilhante. Pasta rosada, dura, com muitas calcites.

Proveniente da zona de São Francisco (6). N. ${ }^{\circ}$ de inv. do Museu: 4878.

CANTABER, oleiro de Tricio, da 2.a metade do séc. I, inícios do II. Já se encontrava atestado em Alcácer.

39. [FLJACCI em cartela rectangular, partida à direita (alt. 3,5 mm).

A sem traço horizontal.

Fragmento de fundo e pé de taça (Est. II), forma Dragendorf 27.

Pé alto, triangular, a tender para o arqueado, superfície interna com ranhura de $28 \mathrm{~mm}$ de diâm. Diâmetro do pé $38 \mathrm{~mm}$.

«Verniz» alaranjado, espesso e homogéneo. Pasta rosa-acastanhada, branda, com muitas calcites.

Proveniente do Castelo, encosta sul (3). N. ${ }^{\circ}$ de inv. do Museu: 1153. FLACCVS, oleiro de Tricio, datável da $2 .^{\text {a }}$ metade do séc. I, inícios do II. Já se encontrava atestado em Alcácer.

\section{BIBLIOGRAFIA}

Alarcão, A. Moutinho, 1971, Terra sigillata itálica em Portugal, in «Actas do II Congresso Nacional de Arqueologia», Coimbra, p. 421-432.

Alarcĩo, J., 1983, Portugal romano, Lisboa, 3. a ed.

BÉmont, Colette, 1975, Recherches méthodologiques sur la céramique sigillée de Glanum, Roma.

Delgado, Manuela, Mayet, Françoise e Alarcão, A. Moutinho, 1975

Fouilles de Conimbriga - IV: Les Sigillées, Paris. 
Delgado, Manuela, Luciano dos Santos, 1984, Marcas de oficinas de sigillata encontradas em Braga. I, "Cadernos de Arqueologia», vol. 1 s. II, Braga, p. 49-70.

Dias, Luisa Ferrer, 1978, As marcas de «terra sigillata» do castelo de Alcácer do Sal, «Setúbal Arqueológica», vol. IV, Setúbal, p. 145-154.

Diogo, A. M. Dias, 1980a, Marcas de terra sigillata sudgália em Portugal, Lisboa.

Diogo, A. M. Dias, 1980b, Marcai de terra sigillata itálica em Portugal, Lisboa.

Diogo, A. M. Dias, 1980c, Cerâmica romana de Alcácer do Sal__/, Lisboa.

Diogo, A. M. Dias, 1982, Mais algumas marcas de terra sigillata itálica de Alcácer do Sal, «Arqueologia», 6, Porto, p. 82-86.

Diogo, A. M. Dias, 1984, Noções operatórias sobre «terra sigillata» itálica e sudgálica em Portugal. Alguns aspectos, «Revista de História Económica e Social», 14, Lisboa, p. 49-65.

Godineau, C., 1968, La céramique arétine lisse, Paris.

Lombard, Yvan, 1978, Catalogues des collections archéologiques de Besançon, VI - La céramique sigillée. I - Signatures, Paris.

MAY ET, Françoise, 1978, Les importations de sigillées à Mérida au ler siècle de notre ère. (Sigillées italiques et gauloises). «Conimbriga», XVII, p. 80-100.

MAY E T, Françoise, 1984, Les céramiques sigillées hispaniques, Paris.

Oleiro, J. M. Bairrao, 1951, Elementos para o estudo da terra sigillata em Portugal. I - Marcas de oleiro encontradas no País, «Revista de Guimarães», LXI, Guimarães, p. 81-111.

Oswald, F., e T. D. Pryce, 1920, An introduction to the study of terra sigillata treated from a chronological standpoint, Londres.

OxÉ, A., Comfor T, H., 1968, Corpus Vasorum Arretinorum, Bona (= O-C).

Silva, Carlos Tavares da, Soares, Joaquina, Beirẽo, Caetano de Mello, Dias, Luisa Ferrer e SoAres, Antonia Coelho, 1980-81, Escavações arqueológicas no castelo de Alcácer do Sal (campanha de 1979), «Setúbal Arqueológica», voi. VI-VII, Setúbal, p. 149-218. 
ExANNII

1

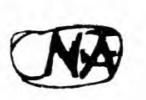

2

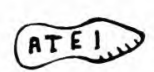

3

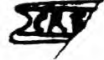

8

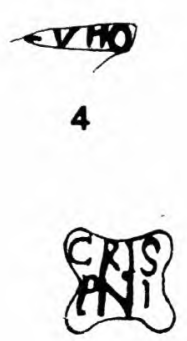

9
$P \cdot N$

5
(1)

6 UED 11

\section{DEMMD}

12
Nosm

13 बi.

14

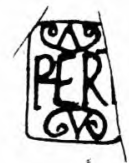

10

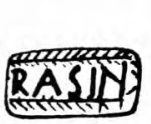

16

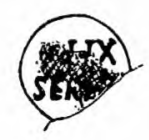

17

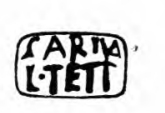

18
(ITT)

$19 \quad 20$
पIIII $\mathrm{VILO}$ 刍 22 23<smiles>[194Nb]</smiles>

24

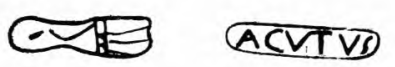

25
(बAD

15
जाए ECAST JFCAS OARRAF
थRONINI
27
28
29
30
31

FFIV
32

\begin{tabular}{|c|c|c|}
\hline PAESTOR & OFPVD & ENICIO \\
\hline 33 & 34 & 35 \\
\hline & VTABR & $\triangle C C l$ \\
\hline & 38 & 39 \\
\hline
\end{tabular}



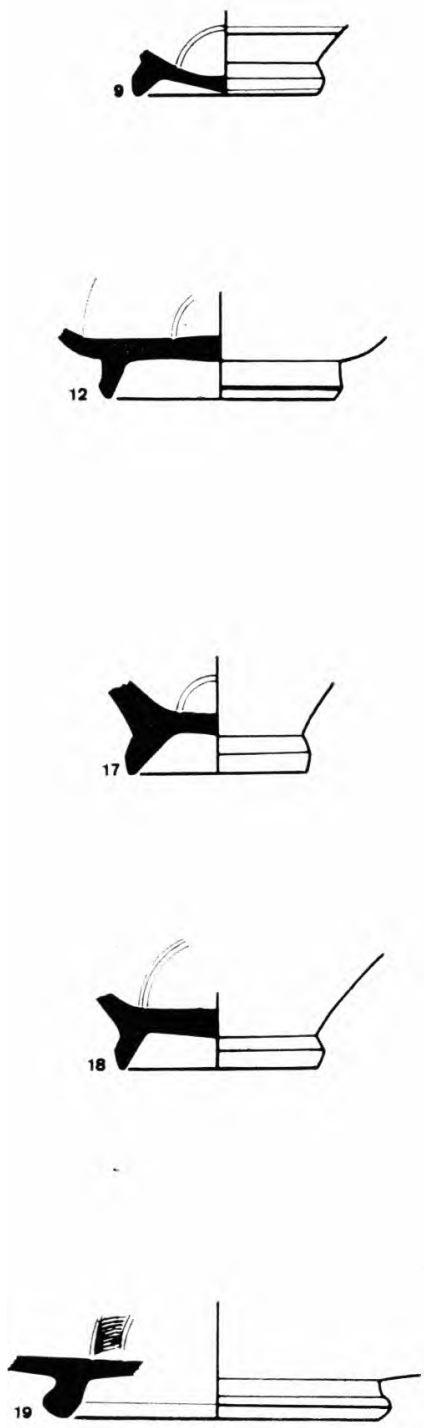

Esc. 1: 2
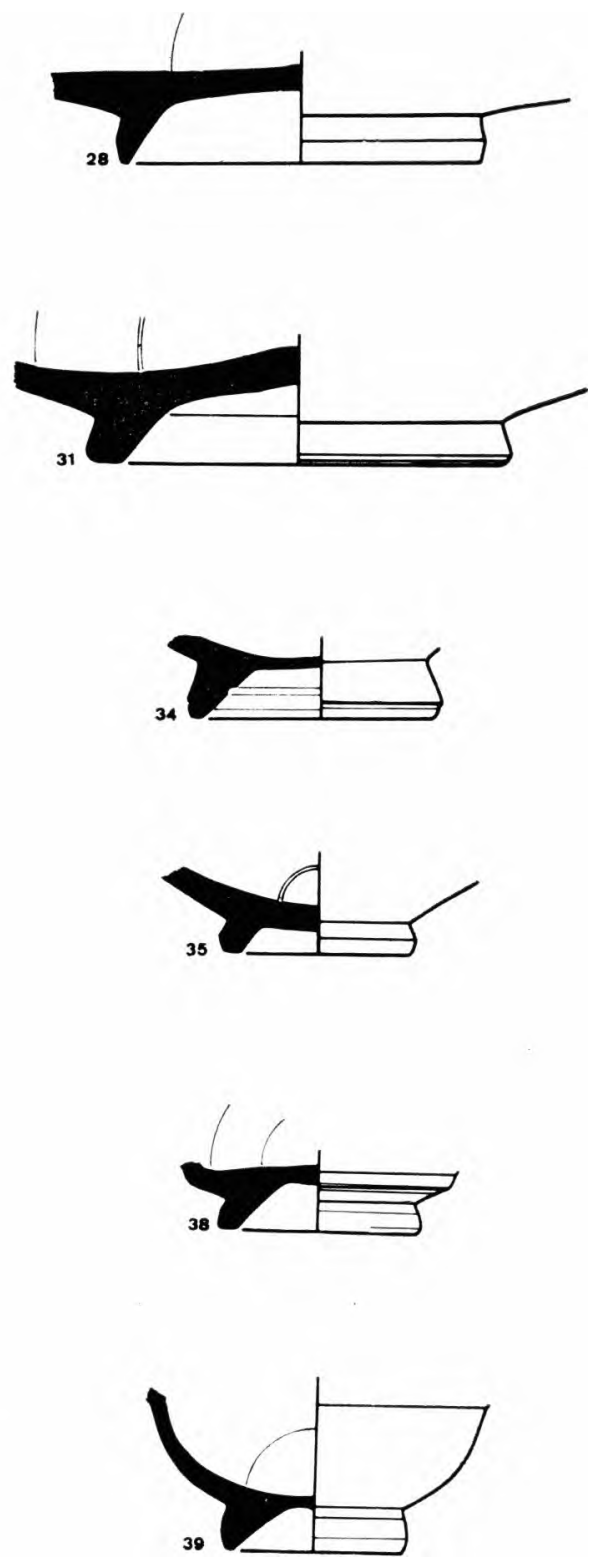